\title{
Spatial-temporal evolution and influencing factors analysis of mortgage assessed price of land use rights in Kunming
}

\author{
Liu Chunxue ${ }^{1 *}$, Zhang Suolin ${ }^{2}$, Xu Shuang ${ }^{3}$ \\ 1,3. School of Urban and Environment, Yunnan Uni versity of Finance and Economics, Kunming, China \\ 2. School of Economics, Yunnan University of Finance and Economics, Kunming, China \\ E-mail: chunxueliu@ynufe.edu.cn
}

\begin{abstract}
Mortgage data for 2014 to 2016 in Kunming were collected in this study, spatial distribution of land assessed price was produced by Kriging and influencing factors were also analyzed. The spatial distribution shows that assessed price of four type mortgage land is gradually decreasing from city center to city periphery and is controlled by supply price and distance from downtown. Economic and policy factors also affect the assessed price of land for different uses or different regions.
\end{abstract}

Keywords-Kunming, Land mortgage market, Land assessment price

The land mortgage market is part of the secondary market of land and plays a positive role in promoting the optimal allocation of land resources, saving intensive use, and accelerating industrialization and urbanization. Assessed price not only reflects the regional changes in land value appreciation and the focus of transactions, but also reflects the direction of economic development to some extent. This paper analyzes the temporal and spatial evolutionary characteristics of the evaluation price of land mortgage market in Kunming, finds out the influencing factors of price evaluation, provides a reference for the pricing of land mortgage market in Kunming and for formulating trading rules for the secondary market of land to promote the transaction of land mortgage market in Kunming.

Current research on land market price mainly includes: land supply price mechanism $(\mathrm{Li}, 2006)$; relationship between land price and economy (Cen, 2013) and research on land mortgage market focuses on: land mortgage assessment issues, risks, etc. (Yan,2007); Land mortgage market price research defines the connotation ( $\mathrm{Zhu}$ and $\mathrm{Ji}, 2002$ ). This paper analyzes the temporal and spatial evolutionary characteristics of the evaluation price of land mortgage market in Kunming, finds out the influencing factors of price evaluation, provides a reference for the pricing of land mortgage market in Kunming and for formulating trading rules for the secondary market of land to promote the transaction of land mortgage market in Kunming.

\section{SPATIAL-TEMPORAL DISTRIBUTION MODELING OF LAND}

\section{MORTGAGE ASSESSED PRICE}

The study area covers Kunming, Yunnan Province in southwest China, which includes Wuhua district, Panlong district, Guandu district, Xishan district and Chenggong district (Figure 1). Construction land, especially concentrated area of mortgage land is main sampling area. There 1064 land mortgage assessed data for 2014 to 2016 were collected.

In this study, geostatistical technique is used to simulate spatial-temporal distribution changes on assessed prices of different uses of land mortgage. Geostatistics has been successfully applied in many fields to predict values or categories of target-regionalized variables at unsampled points, using irregularly distributed, discrete sample data. This approach is based on the principle that nearby data tend to be more related to each other than those far apart (e.g., Desbarats

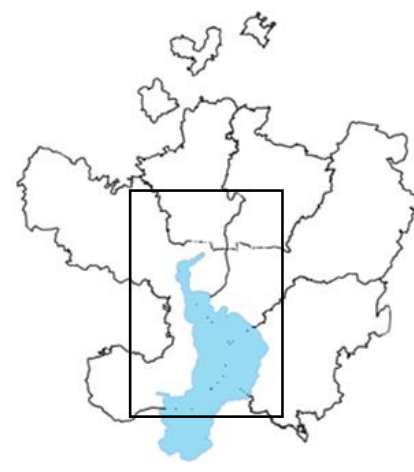

Figure 1 Five districts of Kunming

and Bachu 1994; Yu et al. 2003; Liu and Koike 2007; Iskandar et al. 2012; Rühaak 2015).

Figure 2 shows preliminary data analysis of commercial,
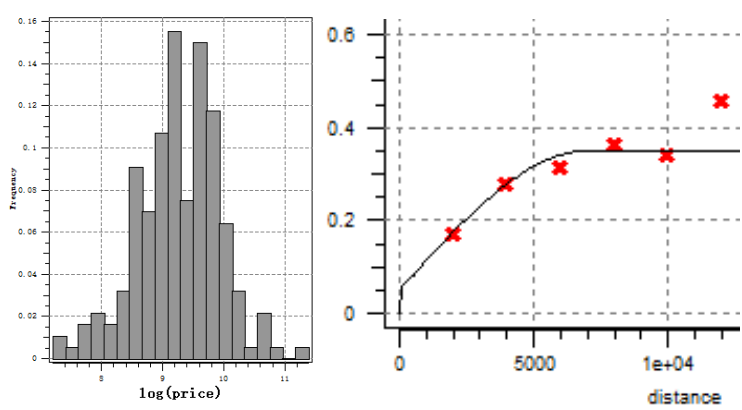

Figure 2 Lognormal distribution of commercial land price and vriogram 
residential, industrial land from 2014 to 2016 in the five districts of Kunming. For mortgaged commercial land price in 2014, the logtransformed data were approximated by a lognormal distribution and were, therefore, valid for stationary conditions and suitable for variography and kriging calculation (Goovaerts 1997; Cressie 1993).

\section{A.Calculation of variogram}

Spatial estimation and prediction by geostatistics are undertaken by deriving the most probable value or category, and generating multiple equiprobable maps using fine-resolution cells in a grid covering the region of interest. The essence of geostatistics is summarized as follows.

Let $\left\{Y(s): s \in D \subset \mathbb{R}^{d}\right\}$ be a real-valued spatially random, stationary function defined in domain $\mathrm{D}$ in d-dimensional Euclidean space $\mathbb{R}^{d}, Z\left(s_{i}\right)$ be observations (samples) of $Y(s)$ at known locations $\left\{s_{1, \ldots, s} s_{k}\right\}$, and the variance of the difference in values at two locations be dependent only on separation distance h. Semivariogram $\gamma_{\mathrm{Y}}(\mathbf{h})$; which measures this variance as a function of $\mathbf{h}$ and expresses the spatial dependence structure of $Y(\mathrm{~s})$, is defined as

$$
2 \gamma_{Y}(\mathbf{h})=\operatorname{Var}\left[\left\{Z\left(\mathrm{~s}_{i}\right)-Z\left(\mathrm{~s}_{j}\right)\right\}\right]^{2}{ }_{\mathrm{g}} \text { for all } \mathrm{s}_{s} \mathbf{s}+\mathbf{h} \in \mathbb{D}
$$

Experimental semivariogram $\gamma_{z}^{*}(\mathbf{h})$ is a discrete expression of Eq. (1), using expectation of the squared difference of a sample pair separated by $\mathbf{h}$, as

$$
\begin{aligned}
& 2 \gamma^{*}{ }_{z}(\mathbf{h})=\mathrm{E}\left[\left\{Z\left(\mathrm{~s}_{\mathrm{i}}\right)-Z\left(\mathrm{~s}_{j}\right)\right\}\right]^{2} \\
& \left\|\mathrm{~s}_{\mathrm{i}}-\mathrm{s}_{j}\right\| \in N(\mathbf{h}) ; i_{i} j=1_{s, \ldots} k
\end{aligned}
$$

where $\gamma^{*}{ }_{z}(\mathbf{h})$ is subsequently fit to a semivariogram model, such as spherical, exponential, Gaussian, or power variograms, as explained in many studies (e.g., Cressie 1993; Goovaerts 1997).

\section{B.The kriging estitmation}

Kriging is termed the best linear unbiased estimator (BLUE) using a semivariogram or covariance. An unknown local mean 1 is filtered from the linear estimator with the unbiased condition, e.g., forcing the sum of kriging weights $\lambda_{i}\left\{i=1_{s \ldots} k\right\}$ to one in ordinary kriging $(\mathrm{OK})$. Under this condition, $\mathrm{E}\left(\boldsymbol{\chi}^{d} \mathbf{Z}\right)=\mathrm{E}\left(Z_{S}\right)=\mathrm{E}\left(Y_{S}\right)$ is satisfied. Using the Lagrange multiplier to incorporate the unbiased condition, $\lambda_{i}$ can be obtained by minimizing the mean squared prediction error $\mathrm{E}\left[\left\{Y_{\mathrm{S}}-\boldsymbol{\lambda}^{s} \mathrm{Z}\right\}^{s}\left\{Y_{\mathrm{S}}-\boldsymbol{\lambda}^{s} \mathrm{Z}\right\}\right.$. For cross validation, $Z\left(\mathrm{~s}_{i}\right)$ is deleted from the sample data set to compare the estimated value of $Z^{*}\left(s_{i}\right)$; as

$$
Z^{*}\left(\mathrm{~s}_{\mathrm{i}}\right)^{-1}=\left\{Z\left(\mathrm{~s}_{1}\right), \ldots, Z\left(\mathrm{~s}_{\mathrm{i}-1}\right), Z\left(\mathrm{~s}_{\mathrm{i}+1}\right), \ldots, Z\left(\mathrm{~s}_{k}\right)\right\}^{s}
$$

\section{CHARACTERISTIC OF SPATIAL-TEMPORAL EVOLUTION ON}

\section{LAND ASSESSED PRICE}

Based on the result of commercial, residential and industrial land assessed price distribution in figure 3 , their spatial-temporal evolution characteristics are summarized as: the spatial distribution of commercial, residential, industrial land, it showed a significant decline from the city center to the periphery of the evaluation of the unit price, the farther away from the center, the lower the evaluation unit price. In the temporal perspective, the activity of land mortgage market declined in 2015, the amount of mortgaged land decreased and the unit price was lower. In the same year, the overall decline in the price of land in Kunming was larger, and the investment in real estate development fell from a year earlier, the two indicators rebounded in 2016. From the above analysis, we can see that the assessed of unit price may be affected by the distance of the mortgaged land from the urban center, economic factors, policy factors, and further quantitative analysis is needed.

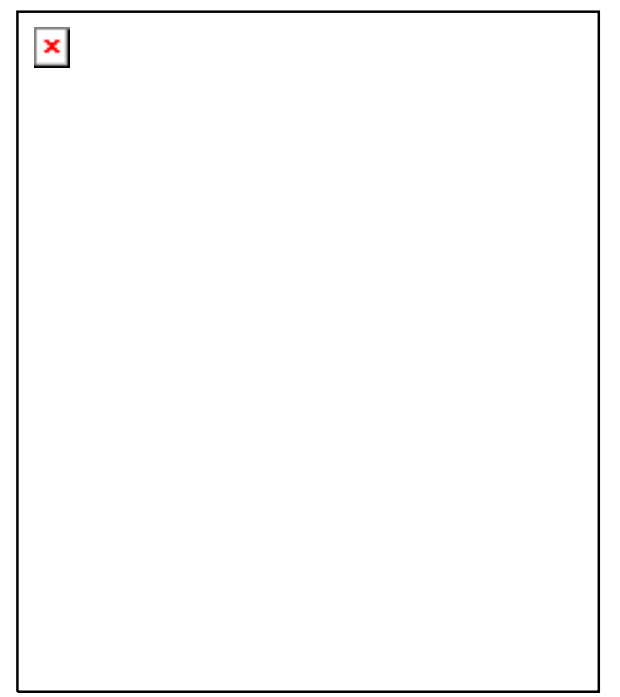

Figure 3 Kiring estimation of land price from 2014 to 2016, which a-c are for 2014, d-f are for 2015, g-i are for 2016 by commercial, industrial and residential order.

\section{INFLUENCING FACTOR ANALYSIS OF LAND ASSESSED}

PRICE

There are 7 factors were selected, including the distance from the center of the Kunming, the price of land supply, the two virtual variables affected by the economic factors, the two virtual variables affected by land use and a random variable. The distance from the junction point to the mortgaged land, which is assumed as $\mathrm{S}_{\mathrm{i}} \mathrm{km}$, is a variable to evaluate the unit price. Real estate investment and valuation prices are set to two dummy variables, $Y_{1}$, $Y_{2}$. Land use types are set two dummy variables $U_{s}, U_{j}$. Land supply price is assumed as $\mathrm{G}$ and other influencing factors are set as $\delta$.

For the 425 data from 2014 to 2016, a multivariate linear regression model is established for these data.

$$
P=C+\beta_{1} G+\beta_{2} D+\beta_{3} U_{S}+\beta_{4} U_{j}+\beta_{5} Y_{1}+\beta_{6} Y_{2}+\delta
$$

P: assessed unit price, C: model constant, G: supply unit price, D: mortgage land to the city center distance; $\delta$ : random error term; $\beta 1$, $\beta 2 、 \beta 3 、 \beta 4 、 \beta 5, \beta 6$ : coefficients; $\mathrm{U}_{\mathrm{s}}, \mathrm{U}_{\mathrm{j}}, \mathrm{Y}_{1}, \mathrm{Y}_{2^{--} \text {-virtual variables. }}$ 
The result of the model fitting is as follows:

$$
\begin{array}{cccc}
P=8482.593+1.0593 G-354.1907 \mathrm{D}+\delta \\
\mathrm{t} \quad(13.44) \quad(16.71) & (-10.77) \\
R^{2}=0.6964 & \bar{R}^{2}=0.6950 \quad F=484.03 & D \cdot W \cdot=1.64
\end{array}
$$

At a significant level of $1 \%$, the model does not have a variance. The $R 2$, $t$ and $F$ statistics are all up to the ideal level. But from DW value, the model has some autocorrelation and needs to be corrected. By using $\mathrm{AR}(1)$, result is follows:

$$
P=8316.211+1.0672 G-341.6659 \mathrm{D}+0.1766 \mathrm{AR}(1)+\delta
$$

$\mathrm{t}$

$$
\text { (13.07) }
$$$$
(-10.54)
$$

$$
R^{2}=0.7051 \quad \bar{R}^{2}=0.7030 \quad F=334.74 \quad D \cdot W \cdot=1.9835
$$

From the economic point of view, land assessed price is mainly affected by the land supply unit price and land position. The land assessed unit price is positively correlated with the land supply unit price, which is negatively correlated with the distance from the city center. From the model, the same distance from the city center of the land, the supply unit price increased 1 yuan/square meters, the evaluation unit price increase of 1.07 yuan/square meters, indicating that after the land development, assessed price growth faster. If the supply unit price unchanged, distance from the city center for each increase of $1 \mathrm{~km}$, the land assessed price reduction is 341.67 yuan/square meters.

\section{RESULT}

From the spatial distribution, commercial, residential, industrial mortgage land assessed price from the city center to the urban periphery gradually decline. The mortgage commercial land distribution is more concentrated, mainly located in the city center and the east of Dianchi Lake, the number of mortgaged residential land is less than commercial land, mainly located in Wuhua, Panlong, Xishan and Guandu, Chenggong area only a small number of mortgaged residential land, distribution is more dispersed; the mortgage industrial land is mainly located in the industrial area outside the city, including economic and technological development zone, High-tech Zone, New Town, High-tech Industrial base, the city center area distribution is less, the evaluation unit price from the city center to the south of Chenggong district gradually decline, the mortgage industrial land part of the urban periphery in the more remote areas, the assessment of the lowest unit price. From the rule of time change, the activity of land mortgage market declined in 2015, the amount of mortgaged land decreased and the unit price was lower. 2015 Commercial and Residential Land assessment Unit price overall decline, the 2016 rebound, but the industrial land has maintained a steady growth trend.

Through multivariate linear regression model analysis, the main influencing factors including the price of land supply and distance from Kunming City Center, the stochastic factors include: economy, policy, real estate price change, etc. The land price of Kunming shows the regularity of decreasing from the city center to the periphery, meanwhile it is influenced by various stochastic factors and shows local difference.

\section{ACKNOWLEDGMENTS}

This work was supported by the National Natural Science Foundation of China Projects (NSFC) number 41562017.

\section{REFERENCE:}

[1]Liu CX, Koike K (2007) Extending multivariate space-time geostatistics for environmental data analysis. Math Geol 39(3):289-305. doi:10.1007/s11004-007-9085-9

[2] Goovaerts P (1997) Geostatistics for natural resources evaluation. Oxford University Press, New York

[3] Cressie N (1993) Statistics for Spatial Data, rev. ed. John Wiley \& Sons. Inc 